\title{
A SEGURIDADE SOCIAL, \\ O SISTEMA ÚNICO DE SAÚdE \\ E A PARTILHA DOS RECURSOS*
}

\author{
Solon Magalbäes Vianna**
}

\begin{abstract}
O artigo esta centrado em quatro questoes que, de alguma forma, afetam a partilha dos recursos do Orçamento da Seguridade Social - OSS, entre os componentes desse sistema (saude, previdencia e assistencia social): O papel do MTPS, "caima" da seguridade e gestor de seu principal programa (benefícios previdenciários); a proposta de vincular os recursos da saúde a determinado percentual do OSS; a controvtrsia quanto as responsabilidades desce orçamento, que tem sido usado para financiar politicas públicas (saneamento, merenda escolar, pagamento de inativos e pensionistas da Uniăo, etc.) que antes eram custeadas pelo orçamento fiscal (recursos ordinários do Tesouro) e, finalmente, a repercussalo da estratégia de contingenciamento adoma pelo governo, atingindo inclusive as contribuiçoes sociais recolhidas pela Receita Federal (FINSOCINL, rancalo sobre lucro e loterias). No final e mencionada a criaça de fonte especfica para saúde e a forma de partiçalo automática entre Unišo, Esbados e Munićpios. O autor conclue com cepticismo em relaçato a soluçbes para o financiamento do sus que nấ passe pela retomada do crescimento economico, combate a sonegaçáo e a inadimplencia de orgalos públicos e empresas privadas e, sobretudo, pela vontade política de fortalecer o sistema de saúde.
\end{abstract}

\section{INTRODUÇÃO}

O conceito de seguridade social - " um conjunto integrado de açōes de iniciativa dos Poderes Públicos e da Sociedade, destinados a assegurar os direitos relativos à saúde, à previdéncia e à assistencia social" (C. F., Art. 194) - constitui uma das mais importantes inovaçőes incorporadas à Constituição de 88.

A novidade estava ausente das intençöes iniciais da Assembléia Nacional Constituinte - ANC. As primeiras versōes do texto constitucional não cogitavam integrar as trés áreas. Inúmeras propostas que, de alguma forma, subsidiaram esses ante-projetos, tanto as oriundas de grupos e entidades da sociedade civil (Rodrigues Neto, 1988) como, em especial, as recomendaçóes da VIII Conferência Nacional de Saúde - VIII CNS (1986) e da Comissão Nacional da Reforma Sanitária - CNRS (1987), propunham solução

- Terto baseado em exposiça feita na Mesa Redonda sobre Financiamento da Saúde no Brasil, realizada em 21-6-91 na Paculdade de Saúde Pública da USP (Ciclo de mesas-redondas: "A crise da saúde: catrangulamento, perspectiva e saida".

- Tecnico do Instituto de Pesquisa Economica Aplicada - IPEA e Presidente da Aseociaça Brasileira de Bconomia da Saúde - ABrES. 
diametralmente oposta, ou seja, separar saúde das áreas de previdência e assistência social. Desta forma, o sistema de saúde passaria a ser financiado com recursos tributários, enquanto as contribuições sociais custeariam somente pensões, aposentadorias e outras prestações de cunho previdenciário e assistencial.

A inovação constitucional trouxe implicações na partição dos recursos da seguridade entre os seus componentes. Este texto analisa essas implicações, em particular aquelas que mais diretamente incidem no sistema de saúde.

\section{ANTECEDENTES}

Até outubro de 88 o sistema público de saúde disputava recursos, no nível federal, em duas arenas distintas. Na primeira, situada na órbita previdenciária, repartia-se o orçamento do Sistema Nacional de Previdéncia e Assistência Social - SINPAS, entre as três grandes linhas programáticas desse sistema: benefícios previdenciários, açōes de assistencia social e atenção médico-hospitalar.

A partição ocorria autonomamente: o orçamento do SINPAS não era apreciado pelo Congresso Nacional e, na prática, sua elaboração não sofria interferência do órgăo orçamentário central. As receitas do SINPAS eram arrecadadas pela própria previdéncia social não se confundindo, por conseguinte, com os recursos que compunham o orçamento fiscal. A contribuição da União para o SINPAS, retirada do orçamento fiscal, era pouco mais que simbólica: entre 1971 e 1988, apenas em dois anos (1971 e 1984) correspondeu a mais de $10 \%$ da receita total do SINPAS. Os dois últimos anos da série registraram as menores taxas $(0,8 \%$ e $0,6 \%)$ (Tabela 1 ).

Na segunda arena, a do orçamento fiscal, os programas a cargo do Ministério da Saúde, concorriam com educaçăo, justiça, transportes, defesa nacional, previdencia do servidor público e demais responsabilidades da Uniåo*.

- Os dois orçamentos, fiscal e previdencifrio, tiveram historicamente importancia bastante deferenciada no financiamento do sistema de saúde. Entre 1990 e 1996 o Tesouro teve participaço relativa crescente (Tabela 2), embora nunca superior a 32,1\%, caindo em 1987 para 27,1\%. 
TABELA 1 - PARTICIPAÇÃO (\%) DAS TRANSFERÊNCIAS DA UNIÃO NO ORÇAMENTO DO SINPAS 1971 - 1988

\begin{tabular}{cccc}
\hline ANO & PORCENTAGEM & ANO & PORCENTAGEM \\
\hline 1971 & 10,9 & 1980 & 5,2 \\
1972 & 9,8 & 1981 & 9,5 \\
1973 & 8,5 & 1982 & 9,7 \\
1974 & 6,9 & 1983 & 8,2 \\
1975 & 6,2 & 1984 & 11,6 \\
1976 & 6,2 & 1985 & 4,4 \\
1977 & 7,1 & 1986 & 3,9 \\
1978 & 5,9 & 1987 & 0,8 \\
1979 & 5,0 & 1988 & 0,6
\end{tabular}

Fontes: Grupo de custeio do MPAS, Balanços do PPAS e SINTESE. In: QLIVERA, F. et al. Metodologia de Projeçao dos Gastos Previdenciários e Assistenciais. Rio de Janeiro, IPEA (INPES) 1990 (Estudos sobre Bconomia do Setor Público, n4)

\section{A CONSTITUIÇÃO DE 88 E O OSS}

A nova Constituição alterou esse quadro. Seu grande avanço foi fazer com que o Congresso Nacional passasse a apreciar (e emendar) não apenas o orçamento fiscal - que durante o regime autoritário apenas homologava mas também os dois outros orçamentos federais: o da seguridade social (OSS) e o investimento das empresas estatais.

Com essa mudança o sistema de saúde passou a disputar recursos em uma só arena, a do orçamento da seguridade social, o que não se tornou necessariamente mais vantajoso para o setor, como se procura demonstrar mais adiante.

Também por definiçăo constitucional (C.F., Art. 195), a seguridade passou a ser financiada, na esfera federal, com recursos do orçamento da Uniāo e das seguintes contribuições sociais:

"I - dos empregadores, incidente sobre a folha de salário, o faturamento e o lucro"

"II - dos trabalhadores"

"III - sobre a receita de concursos de prognósticos" 


\section{TABELA 2 - EVOLUÇÃO DO GASTO FEDERAL COM SAÚDE* E DA PARTICIPAÇÃO (\%) DAS DIFERENTES FONTES 1980 - 1987}

Em Cz\$ 1 milhão de 1987

\begin{tabular}{lrrcc}
\hline ANO & TOTAL & \multicolumn{2}{l}{ FONTES } & \\
\hline & & FPAS** & TESOURO*** & OUTRAS**** \\
\hline 1980 & 193.229 & $\mathbf{8 2 , 9}$ & 14,3 & 2,8 \\
1981 & -180.514 & 81,2 & 16,3 & 2,5 \\
1982 & 189.811 & 79,0 & 18,7 & 2,3 \\
1983 & 154.294 & 75,4 & 23,2 & 1,4 \\
1984 & 161.249 & 77,6 & 21,6 & 0,8 \\
1985 & 192.650 & 70,9 & 28,3 & 0,8 \\
1986 & 214.740 & 67,5 & 32,1 & 0,4 \\
1987 & 298.562 & 72,5 & 27,1 & 0,4 \\
\hline
\end{tabular}

* Inclui despesas com programas de Alimentaço e Nutriça. Năo inclui os gratos com Saneamento e Proteça ao Meio Ambiente.

* Fundo de Previdencia e Assistencia Social.

*** Inclui recursos do PINSOCIAL.

**** Inclui FAS (CEF)

Ponte: IPEA. Coordenadoria de Saúde e Previdencia Social. A Conta Social Revisirada, 1980-1987. (Acompanhamento de Políticas Públicas, no 11).

Com orçamento próprio e fontes vinculadas, o passo seguinte para aumentar o grau de autarquizaçăo da seguridade social, seria atribuir-lhe competência para o recolhimento de todas as contribuiçōes sociais. Tal pretensão não prosperou. A responsabilidade sobre a arrecadação das contribuiçóes sociais sobre o faturamento, lucro e concursos de prognósticos ficou com a Receita Federal. A seguridade social, manteve a prerrogativa histórica da previdencia social, sobre o recolhimento das contribuições sobre folha de salário (Lei n9 8212/91, Art. 33). Essa fonte deverá representar, em 1992, cerca de 47\% dos recursos do OSS (Piola \& Vianna, 1991).

\section{A PARTILHA ORÇAMENTÁRIA}

Ao se integrar à previdencia e à assistencia social, o SUS entrou em uma 
competição que lhe é desfavorável. O custeio das prestações a cargo do INSS (pensões e aposentadorias, principalmente) demanda um volume crescente de recursos que, a médio e longo prazo, tende a absorver a totalidade das contribuições sociais. Ao mesmo tempo, o governo tem mantido em valores insatisfatórios* as transferências do Tesouro para o OSS previstas na Constituição (C.F., Art. 195, caput e Art. 198, Parágrafo único), como passou, ainda, a incluir entre as responsabilidades da seguridade social, o financia-

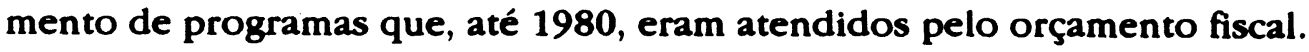

Tudo isto torna cada vez mais problemático o financiamento do SUS. A fatia de 30\% habitualmente pleiteada pela saúde é poucas vezes alcançada mesmo antes da Constituição de 88 - embora sabidamente aquém do necessário para prover, com padrőes qualitativos aceitáveis, o acesso universal e equalitário às açóes e serviços de promoção, proteção e recuperação da saúde (C.F., Art. 196), começa a configurar-se como uma imagem-objetivo cada vez mais distante. Entre 1971 e 1988 somente em 4 exercícios orçamentários as despesas do INAMPS atingiram percentual superior a $30 \%$ do dispéndio total do SINPAS (Tabela 3); a média do período foi de $28,1 \%$ (Oliveira et al., 1990).

\section{TABELA 3 - PARTICIPAÇÃO (\%) DO INAMPS NAS DESPESAS DO SINPAS 1971 - 1988}

\begin{tabular}{cccc}
\hline ANO & PORCENTAGEM & ANO & PORCENTAGEM \\
\hline 1971 & 27,9 & 1980 & 27,3 \\
1972 & 26,4 & 1981 & 24,3 \\
1973 & 26,8 & 1982 & 23,3 \\
1974 & 26,5 & 1983 & 21,9 \\
1975 & 29,2 & 1984 & 25,3 \\
1976 & 31,5 & 1985 & 26,7 \\
1977 & 30,5 & 1986 & 25,2 \\
1978 & 29,8 & 1987 & 37,8 \\
1979 & 27,6 & 1988 & 38,1 \\
\hline
\end{tabular}

Fonte: OLVEIR, F. Op. cit.

Nota: Media de 28,1\% entre 1971 e 1988.

- A contribuiça da Uniáo (recursos ordinarios do Tesouro) em 1992 devera representar apenas 7,2\% da receita tocal da seguridade social (Camara dos Depubados, Diretoria Legislativa, 1991). 
Esse cenário em uma conjuntura econômica recessiva, onde as receitas públicas costumam decrescer, gera uma disputa perversa por recursos escassos. De um lado, pensões e aposentadorias, de outro, os serviços de saúde. É certo que essa disputa já existia no SINPAS: a assistência médica concorria com os benefícios previdenciários e a assistência social. A diferença é que, agora, a competição não se limita a assistência médico-hospitalar, mas alcança todos os serviços de saúde.

Estes dificilmente deixam de ser sacrificados: uma coisa é competir com iniciativas de prioridade duvidosa, como os projetos de construção do caça subsónico AMX, do submarino nuclear ou da ferrovia norte/sul, o que aconteceria se saúde fosse financiada com recursos tributários, conforme proposto pela VIII CNS. A luta não seria fácil, mas a opinião pública, reforçada pela pressão internacional em favor da redução dos gastos militares, estaria a favor. Outra coisa, porém, é concorrer com mais de 12 milhóes de aposentados e pensionistas cuja sobrevivência está, na grande maioria dos casos, condicionada ao recebimento regular de modestos benefícios.

\section{ALGUMAS QUESTŐES}

\section{O Papel do MTPS}

A primeira questão - não necessariamente a mais importante - envolvendo a partilha dos recursos dentro da seguridade social, está relacionada com o duplo papel do Ministério do Trabalho e Previdéncia Social. O MTPS é, simultaneamente, gestor dos programas de maior porte financeiro como pensōes, aposentadorias, seguro desemprego e saúde do trabalhador e o caixa da seguridade social. As contribuiçőes sociais diretamente arrecadas pelo MTPS (taxaçäo sobre folha de salário) representaram em 1990 mais de $80 \%$ da receita global da Seguridade Social (Informe de Previdência Social, n 4, 1991).

Essa situação peculiar concentra poder político nas mãos do titular do MTPS, dados os inúmeros instrumentos à sua disposição que permitiriam favorecer os programas sob sua gestão em inevitável detrimento dos demais. Em contrapartida torna-o alvo preferencial das pressóes dos lobbies setoriais para liberação de recursos, o que, se de um lado, pode ser eventual- 
mente desconfortável, de outro, representa uma valiosa oportunidade para exercer poder político. Por exemplo: se o MS atrasar o pagamento de médicos e hospitais contratados ou retardar repasses para Estados e Municípios por não ter recebido recursos do MTPS, nada mais natural que a Associação Médica Brasileira, a Federação Brasileira de Hospitais - FBH ou governadores e prefeitos, desviem o foco de suas pressões para o Ministro da Previdéncia Social de forma a terem seus créditos liberados.

Não há evidência de que situações como essa tenham ocorrido. Mas a sua possibilidade, dada as características de nossa prática política, é um risco sempre presente: a integração conceitual, inerente à definição constitucional de Seguridade social, não se reproduziu sob a ótica organizacional, o que aconteceria com a integração da saúde, assistência e previdência social em um só Ministério (Ministério da Seguridade Social). Entretanto, a unidade de comando, princípio coerente com o conceito de seguridade e com a tentativa de enxugamento da máquina federal anunciado nos primeiros dias do atual governo, não se concretizou. Ao contrário, ações típicas da seguridade estão hoje diluidas em pelo menos quatro ministérios: Educação, Saúde, Trabalho e Previdência Social e Ação Social.

\section{A vinculação}

Uma suposta solução, repetidamente apontada (Rodrigues Neto, 1988) para garantir recursos para saúde é a fixaçāo de um percentual mínimo do OSS para esse setor. Esse singelo expediente tem mero efeito " psicológico"; a vinculação na prática, se limita a posiçăo orçamentária inicial que pode ser - como tem sido - bastante alterada ao longo do exercicio financeiro (Piola \& Vianna, 1991).

Por determinação constitucional (C.F., ADCT, Art. 55), 30\%, no mínimo, do OSS - excluído o seguro desemprego - deveriam ser destinados à saúde, até que fosse aprovada a primeira Lei de Diretrizes Orçamentárias - LDO, uma outra inovação da nova Constituição (C.F., Art. 165). A tentativa protecionista não teve eficácia. A nova Constituiçāo só entrou em vigor em outubro de 88, o que impediu a adoção do OSS em 89. Estimativas para esse ano (1989) sugerem que no conjunto dos gastos com saúde, previdência e assistência social, a primeira área tenha recebido $28,6 \%$ do total dos recursos (Azeredo \& Lobo, 1991). 
A primeira LDO (Lei $\mathbf{n}^{9} \mathbf{7 8 0 0 / 8 9}$ ) editada para orientar a elaboração do orçamento de 1990 , bem como a segunda (Lei $n^{8}$ 8074/90), dispondo sobre as diretrizes orçamentárias para 1991, não mantiveram a vinculação, restabelecida, entretanto, para o orçamento de 92 (Lei n 8211/91).

A vinculação, por si só, não assegura maiores recursos, particularmente em um ambiente de crise fiscal ou quando a prioridade da área beneficiária nāo tem contornos nítidos.

Um bom exemplo dessa incerteza e da fragilidade da vinculação como panacéia para um problema de escassez de recursos e/ou de vontade política, pode ser encontrado na área de educação. A despeito de protegida pela Constituição (C.F., Art. 212) que obriga a União a aplicar no desenvolvimento da educação, $18 \%$ da receita de impostos*, os recursos federais para esse setor tiveram queda real em $1990 \mathrm{em}$ relação ao ano anterior. Conforme o critério adotado para contabilizar os gastos educacionais, a queda pode ter chegado ao desastroso patamar de $30 \%$ (Piola, Vianna \& Camargo, 1992) ou ter sido meramente residual (Marques, 1991).

Ademais, o mandamento constitucional é negligenciado. Muitos Estados e Municípios não o cumprem. E a União, para efeito de dá-lo como atendido, computa como em educação despesas que, em outras circunstancias, são consideradas como pertencentes às Funções "Saúde e Saneamento" e "Previdência e Assistência" **.

A afronta recai também sobre o dispositivo que obriga o Poder Público a aplicar nos dez primeiros anos de promulgaçăo da Constituiçăo, " pelo menos, cinqüenta por cento dos recursos a que se refere 0 art. 212 da Constituiçăo, para eliminar o analfabetismo e universalizar o ensino fundamental" (C.F., ADCT, Art. 60). Neste caso o descumprimento não é de Estados e Municípios. Estes já vinham exercitando essa política mesmo antes de promul-

\footnotetext{
- Bandos e Municipios: 25\%.

* Gastos com merenda escolar (eub-programa Alimentacto e Nutriço e com o pagamento de pessoal inativo do MBC (Lei n 7348/8s), por exemplo.
} 
gada a atual Constituição. A União é que se julga desobrigada de fazê-lo, alegando näo ter sob sua responsabilidade uma rede de ensino fundamental, como acontece com os demais entes federativos. Sob esse argumento destinou em 1990 apenas 6,6\% de sua receita de impostos para o ensino básico (Amaral Sobrinho, 1991).

\section{Responsabilidades do OSS}

O terceiro problema da partilha de recursos dentro da seguridade social diz respeito a controvérsia em torno do que pode ou não pode ser financiado pelo OSS.

A Constituição e a, assim chamada, lei orgânica da saúde (Lei n? 8080/90) não são - como as trés Leis de Diretrizes Orçamentárias já promulgadas não foram - suficientemente explícitas sobre a matéria. É a indefinição ou a ambigüidade que, ao fim e ao cabo, abrem a brecha necessária para contrabandear para dentro do OSS, programas que antes de 88 não compunham o orçamento da saúde, da previdência ou da assistência social.

Assim, a proposta orçamentária para 1992 obedeceu a LDO (Lei n? 8211/91, Art. 28, Parágrafo 39) destinando para saúde 30,6\% do orçamento da seguridade social, excluindo o PIS/PASEP. Esse percentual, no entanto, só foi alcançado com a inclusăo no ámbito da saúde, dos gastos com saneamento básico, apoio nutricional, hospitais universitários, saúde do trabalhador, saúde escolar, merenda escolar, assisténcia médico-odontológica de servidores públicos e construçăo de CLACs, além de encargos com inativos e pensionistas do MS. A maior parte dessas despesas, até 1988, era atendida com recursos tributários que conformam o orçamento fiscal e não pelas contribuiçőes sociais, principal fonte do OSS (Britto, 1991).

Por essa razão, o Deputado Antonio Britto entende que " em 1992, nós, da saúde, sentiremos saudades do ano que passou", pois $20 \%$ dos recursos setoriais vão para atividades que antes não eram compreendidas pelo setor (Britto, 1991).

A questão é controvertida em boa parte pela falta de definição sobre o que seja ou não responsabilidade do setor de saúde ou, mais amplamente, da 
seguridade social. É o caso das atividades acima mencionadas e também do pagamento de inativos e pensionistas da União que sempre foi atendido com recursos do Tesouro. Desde que foi criado o OSS essa prestação passou a ser custeada com recursos do FINSOCIAL. Em 1990, somente para essa finalidade foram utilizados cerca de Cr\$ 89 bilhões, o equivalente a $18 \%$ da arrecadação do FINSOCIAL.

A manutenção de hospitais universitários e a execução de programas de saúde ocupacional, eram - antes do advento da seguridade social - custeadas com recursos do orçamento (Tesouro) do MEC e do MTb, respectivamente. Os recursos da Previdéncia (INAMPS) repassados, através de convênio, aos hospitais universitários destinavam-se a remunerar a atenção médica prestada à clientela previdenciária. São, todavia, serviços de saúde de caráter universal e definidos na lei orgânica da saúde como de responsabilidade do SUS (Lei n' 8080/90) e, portanto, da seguridade social (C.F., Arts. 198 e 200).

A construção de CIACs, porém, só poderia ser atendida pelo OSS no seu componente médico-sanitário e de assistencia social. $O$ projeto pedagógico deve onerar o orçamento da educação e parece que assim está acontecendo, embora o Ministro da Saúde (Alceni Guerra) não considere os CIACs como escola (Constancio, 1991.)

A questão do saneamento é menos trivial. Investimentos em água e esgoto são atendidos majoritariamente com recursos do FGTS. Mas o Ministério da Saúde - MS, através da Fundaçăo Nacional de Saúde - FNS, sempre aplicou recursos do Tesouro a fundo perdido em saneamento como estratégia para combater doenças de veiculaçăo hídrica. Em média, entre 1980 e 1987 perto de $20 \%$ desses investimentos foram financiados pelo Tesouro (IPEA, 1989).

Aparentemente, não é questionável que o OSS financie açōes nesse campo. Afinal o saneamento contribue de forma significativa para melhorar o nível de saúde. Ném disso, cabe ao SUS participar da formulação da política e da execução das ações de saneamento básico (C.F., Art. 200, IV). Nada obstante, poder-se-ia alegar que os programas de saneamento não tém exclusiva finalidade sanitária. E participar da execução, como cabe ao SUS, não significa, obrigatoriamente, que as açöes respectivas tenham que ser custeadas pelas contribuições sociais. Por que não custeá-las com as transferências (re- 
cursos ordinários do Tesouro) da União para o OSS?

Já o financiamento da assistência médico-odontológica de servidores públicos leva a um outro tipo de conflito conceitual. Financiá-la pelo OSS, vale dizer, com as contribuições sociais, se justificaria apenas pela "lógica" de se tratar de serviço de saúde e, como tal, atribuição da seguridade social.

O que se configura inusitado, para valer-se de um eufemismo, é o uso das contribuições sociais, fonte exclusiva da seguridade social, para atender esse compromisso. Ao criar o SUS institucionalizando o acesso universal e igualitário aos serviços de saúde (C.F., Art. 196), a Constituição Federal teria vedado, ainda que não explicitamente, o uso de recursos da seguridade para subsidiar, total ou parcialmente, serviços diferenciados para clientelas fechadas. Estimativas, ainda que pouco recentes, indicam que o gasto governamental per capita com a saúde do servidor público federal* seria cerca de $30 \%$ e $750 \%$ superior às despesas de finalidade similar com a população urbana e rural, respectivamente (Vianna, 1989). A magnitude da diferença dá bem a medida do grau de desigualdade do sistema de saúde brasileiro.

A única justificativa razoável para que essas atividades sejam custeadas com recursos públicos, está em considerá-las como fringe benefits dentro da política de recursos humanos para o setor governamental; aceita esta hipótese, a fonte de financiamento teria de ser a receita fiscal da Uniảo.

A favor da inclusão do custeio da merenda escolar pelo OSS pesa o fato de se tratar de atividade enquadrada em Alimentaçäo e Nutrição um subprogama orçamentário típico do Programa Saúde (Função Saúde e Saneamento). Acreace a eaca peculiaridade, o mandamento constitucional segundo o qual a alimentação e a assisténcia à saúde escolar devem ser financiadas com recursos provenientes de contribuiçóes sociais e outros recursos orçamentários. (C.F., Art. 212, Parágrafo 49).

- Ercluidos os trabalhadores e dependentes das empresas escanis. A incluselo desea clientela cervamente elevaria o gasto per capita com saúde dos servidores públicos. 
Em oposição a essa tese, sustenta-se que o financiamento poderia ser atendido por outra contribuição social, no caso em questão o salário-educação, e não por aquelas que foram definidas (C.F., Art. 195) para compor o OSS. No contexto brasileiro a merenda escolar tem impacto meramente residual na elevação do status sanitário. Trata-se de programa cujos objetivos são essencialmente educacionais: reduzir o absentismo escolar e melhorar o aprendizado, pouco ou nada tem a ver, ao menos diretamente, com as prioridades do sistema de saúde. Essas prioridades no campo da alimentação e nutrição contemplam essencialmente gestantes, nutrizes e pré-escolares.

Enquadrar a merenda no campo da assistência social para justificar o seu financiamento pela seguridade, impediria a extensão dessa ação a toda a rede oficial de ensino. Por definição constitucional (C.F., Art. 203) a assistência social destina-se à proteção da população carente não tendo, portanto, o caráter universal das ações desenvolvidas pela escola pública.

\section{O contingenciamento}

A centralização da receita de todas as contribuições sociais no Instituto Nacional de Seguridade Social - INSS, se fosse efetivada, diminuiria a interferência das autoridades fazendárias. Nesse caso apenas uma parte da receita federal (Imposto de Renda, IPI, IOF, etc...) continuaria sob sua gestão. A outra parcela, representada pelos novos "impostos" vinculados (taxação sobre o lucro das empresas, o faturamento e a receita das loterias) previstos no Art. 195 da Constituição Federal e, ainda, a tradicional contribuição sobre a folha de salário, seriam arrecadadas e geridas pelo INSS.

A idéia oposta visava a unificaçäo de todas as receitas federais no Ministério da Economia, Fazenda e Planejamento - MEFP. Esta opção, defensável sob o ponto de vista da administraçăo financeira, năo tem tido viabilidade política. Entidades de trabalhadores e de empresários, aliadas à burocracia previdenciária tem oposto forte resistencia à tese integracionista.

Prevalece a alternativa intermediária, mantendo inalterada a correlaçăo de forças entre as burocracias fazendária e previdenciária. O INSS fiscaliza e arrecada a contribuição sobre folha de salário, como fazia antes dele o IAPAS, enquanto a Receita Federal preserva sua hegemonia sobre os "impostos" incidentes no faturamento e lucro das empresas e nos concursos de prognós- 
ticos.

Satisfatória como solução de compromisso para pôr fim a disputas, a alternativa adotada, entretanto, pode ter facilitado o contingenciamento de parte expressiva da receita gerada pelas contribuiçōes sobre o lucro e sobre o faturamento das empresas.

Em 1990, segundo dados do próprio MEFP, dos Crs 168 bilhões arrecadados como contribuição sobre o lucro das empresas, $\mathrm{Cr} \$ \mathbf{5 8 , 5}$ bilhōes (34,6\%) ficaram retidos no Tesouro. De um total arrecadado de Cr\$ 482,5 bilhōes, como taxação sobre o lucro das empresas, Cr\$ 101 bilhões (21\%) também não foram liberados até dezembro. Não aconteceu diferente com a receita gerada pelos concursos de prognósticos: recolhidos $\mathrm{Cr} \mathbf{2 1 , 8}$ bilhöes, foram contingenciados Cr\$ 7,4 bilhöes ou 33\% (Britto, 1991).

A esperança de solução para problemas como a retenção dos recursos arrecadados pelo MEFP e a utilização do FINSOCIAL para custear o pagamento de inativos e pensionistas da União* pode estar na Lei Organica da Seguridade Social.

Por essa Lei (Lei $\mathbf{n}^{9}$ 8212/91, Art. 19), o Tesouro fica obrigado a repassar a receita de contribuiçōes vinculadas à seguridade social, nos mesmos prazos em que ocorre a distribuição dos recursos do Fundo de Participação dos Estados - FPE e Fundo de Participação dos Municípios - FPM.

O mesmo ato (Lei n` 8212/91, Art. 17) estipula um cronograma até 1995 para diminuiçäo gradual da utilizaçăo dos recursos da seguridade social no pagamento de inativos e pensionistas da União, bem como estabelece as condiçóes para o uso das contribuiçóes sociais no pagamento de pessoal e custeio da administração geral dos órgăos que compóem a seguridade social (Lei n 8212/91, Art. 18).

\section{CONSIDERAÇÓES FINAIS}

De qualquer forma a partilha dos recursos do OSS poderia estar sendo ainda mais desfavorável ao sistema de saúde. Năo o foi porque o gasto do

- Att o advento da seguridade soctal eseas despeases eram atendidas pelo Orçamento Fiscal (recursos ordinírios do Tesouro) da Unito e, o que nilo mudou, pelas contribuigées dos servidores ativos. 
INSS com prestações em dinheiro (pagamento de pensões e aposentadorias, principalmente), foi mantido represado até o ano passado.

A demora na implementação da Lei de Custeio da Previdência Social (Lei n 8212/91), retardou por mais de 2 anos a adoção das novas regras para o cálculo do valor das aposentadorias, mais favoráveis ao trabalhador (C.F., Art. 201, Parágrafo $3^{\circ}$ ) e a equiparação dos benefícios rurais aos urbanos. Até mesmo o dispositivo constitucional (C.F., Art. 201, Parágrafo 59) que se supunha auto aplicável, segundo o qual nenhum benefício pode ter valor mensal inferior ao salário mínimo, teve que esperar a instituição do Plano de Custeio para a sua efetivação. Enquanto o veto total à Lei Orgânica da Assistência Social, adiou indefinidamente as despesas com o pagamento de um salário mínimo mensal para os deficientes carentes (C.F., Art. 203, V). Se essas medidas estivessem em vigor desde 89 , provavelmente o financiamento do SUS teria sido ainda mais insatisfatório.

A uma conjuntura recessiva se contrapõe uma abundante safra de projetos para criar recursos novos. As sugestões vão desde o puro e simples aumento das aliquotas de contribuições até a inovação do imposto único sobre transações financeiras. A primeira, tentada recentemente, foi repelida pelo Congresso Nacional. A segunda, porém, dado o inegável fascínio da simplificação do seu recolhimento, pode concretizar-se no bojo de mais uma reforma tributária, ainda que - ironicamente - como um imposto adicional, para enredar ainda mais o cipoal tributário brasileiro. Ambas são politicamente difíceis, quer pela resistencia, generalizada na sociedade, à voracidade fiscal, quer, no caso do imposto " único", pelo temor de mudanças radicais, se esse imposto vier a ser adotado na forma em que foi originalmente concebido.

Como habitualmente acontece quando se discute o financiamento do sistema de saúde, retorna a pauta a proposta da instituição de fonte(s) específica(s) para o setor. A par dos conhecidos inconvenientes das vinculaçóes, a idéia tem dois méritos. Por um lado anula a disputa entre "aposentadorias e hospitalizações" referida neste texto. Por outro, cria a oportunidade de automatizar a partilha de recursos entre os entes federativos (União, Estados $e$ Municípios) integrantes do SUS; a partição ocorreria em modalidade similar ao FPE e FPM. Com isto estaria neutralizando o casuísmo inerente às transferencias negociadas e dar-se-ia efetividade ao princípio constitucional da 
descentralização do sistema de saúde.

Entretanto, para que haja aporte de recursos novos haveria a necessidade de fonte adicional, o que remete à polêmica sobre a já excessiva carga fiscal. Na verdade, dados os constrangimentos gerados por uma economia em crise, parece difícil outra alternativa que não envolva: um forte combate à sonegação e à inadimplencia de empresas privadas e órgãos públicos, sobretudo em relação às contribuições sociais, a retomada do crescimento econô. mico e a vontade política de fortalecer o sistema de saúde sem o que, mesmo resolvidas as duas primeiras questóes, o financiamento da saúde no Brasil continuará nos seus históricos níveis de pobreza.

\section{BIBLIOGRAFIA}

1 AMARAL SOBRNHO, J. O governo federal e os $18 \%$ do orgamento para a educagio. Brasilia, IPEA, 1991. (Relatorio interno $n \circ 4)$.

2 AZEREDO, B. \& LOBO, T. Polttica social: regulamentagdo constituctonal e procases orgamentdrio; Relatório ao PNUD - Programa das Naçbes Unidas para o Desenvolvimento, 1991.

3 BRASIl. Constituiçäo, 1988. Consttutgeio: Repablica Federativa do Brastl, 1988. Brastlia, Senado Federal, 1988.

4 BRASIl. Camara dos Depundos. Asecseoria legislativa - Análise da proposta orçamentária da seguridade social. In: PIOLA, S.P. \& VINNA, S. M., Conta soctal consolidada (1980-1990), Versio preliminar. Brasilia, IPEA, 1992. p. - .

5 BRASIl. Comiselo Nacional da Reforma Saniciria. Proposta para o componame sando na nova Constitutcaio brastletra. Rio de Janeiro, s.d. (Documentos ii).

6 BRASIL. PBA. Coordenadoria de Saude e Previdencia Social. A conta soctal revtstlada 1980-1987. Brastia, IPEA, 1999 (Acompanhamento de Politicas Publicas, ne 11)



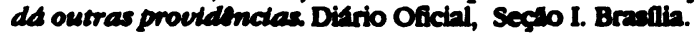

8 BRAsL. Lei ne 7.800, de 10 jul. 1909: dippose sobre as dirotribes orgamentertas para o ano de 1990 e da outras provtdenctas Difrio Oicial, Segfo L, Brastia, 11 jul. 1989, p. 11388.

9 BRAsI. Let ne 8.074, de 31 jul. 1990: dipose sobre as difretritens orgamentdrtas para o ano de 1991 e da outras provtdencias. Ditrio Oficial, Segto I, Braetia, 1 ago. 1990. p. 14631.

10 BRASI. Lei 9 8.080, de 19 de set. de 1990: depos sobre as condigies para a promogeio, protegdo • recue

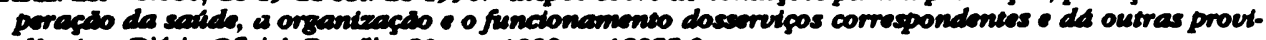
dinctas Ditrio Oficial, Brastia, 20 set., 19\%0. p. $18055-9$.

11 BRASI. Lei ne 8.211, de 22 jul. 1991: dipose sobre as diretrters orcamentarlas para 0 ano de 1992 e da outras proetdincias Ditrio Oficial, Secto l, Brantia, 23 jul. 1991. p. 14601.

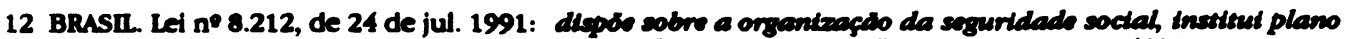
de custedo e did outras proetdenctar Ditrio Obcial, Segto L, Brastia, 25 jul. 1991. p. 14801.

13 BRASIL. Minibuerio do Trabalho e Previdencia Social. Informe de Previdencta Soctalne 4. Bradia, 1991.

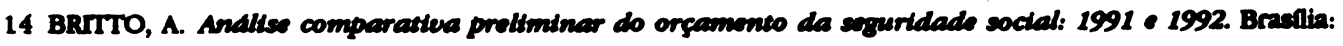


Camara dos Deputados. Diretoria Legislativa, 1991.

15 BRITTO reclama do orçamento. Correio Brasiliense, Brasilia, 7 dez. 1991.

16 Noca do Deputado Antonio Brito sobre as informaçoes prestadas pela ministra Zelia Cardoso de Mello (referente ao FINSOCLLL e d contribuiçao de Pescoa Juridica).

17 CONSTANCIO, P. Calmon propoe verba dos CIACs para universidades. Corrolo Braediliense, Brastlia, 8 dez. 1991. p. 11.

18 MARQUES, A. E. Despeseas gouernamentads com educagio: 1986-1990. Brastia, NIPEA, 1991 (Terto para discusesto n' 243).

19 OLIVEIRA, F. et al. Motodologta de projegido dos gastos proutdonctarlos e assistemetats. Rio de Janeiro: IPEA, 1990 (Bstudos sobre Bconomia do Setor Público ne 4)

20 PIOUA, S. F.; VINNA, S. M.; CAMARGO, S. F. Conta soctal concolidada (1980-1990); Versto preliminar. Brastlia, IPEA, 1992.

21 PIOLA, S. F. \& VINNA, S. M. Poltticas e prioridades do SLstema Único de Sacido: Verséo preliminar. Brasflia, 1991.

22 RODRIGUEZ NETO, E. Saudh: promessas e limites da Constitutgdo. Salo Paulo, 1988. [Tese de Doutoramento - Faculdade de Medicina da USP].

23 VINNN, S. M. Equitdade dos servitgos do sauide. Beasilia, IPEA, 1989. (Terto para discusseso ne 24).

[Now dos Ed.] O desmembramento do Miniaterio do Trablho e Previdencia Social, posterior ao recebimento do artigo, nato invalida as consideraçoes do Autor. 